\title{
FAMILY CARS' LIFE CYCLE COST (LCC) ESTIMATION MODEL BASED ON THE NEURAL NETWORK ENSEMBLE
}

\author{
Xiaochuan Chen ${ }^{1}$,Jun Shao ${ }^{1}$,Zhongxu Tain ${ }^{2}$ \\ 'The Mechanical Engineering College, Donghua University, Shanghai 200051, China \\ Email:xcchen@dhu.edu.cn ;'Internal Combustion Ebgin Institute, Shanghai Jiaotong \\ University, 200030
}

Abstract: Design for cost (DFC) is a method that reduces life cycle cost (LCC) at design stage. From the angle of $\mathrm{DFC}$, the design features of family cars were obtained, such as all dimensions, engine power and displacement. At conceptual design stage, cars' LCC were estimated using back propagation (BP) artificial neural networks (ANN) method based on the features. An example was given. Levenberg-Marquardt (LM) and Genetic algorithm (GA) were used to train BP ANN' $s$ weights. The results obtained through the adoptions of neural network ensemble is better than simply use GA or LM algorithm.

Key words: life cycle cost (LCC); artificial neural networks (ANN) ensemble; family cars

\section{INTRODUCTION}

Now family cars have become popular among some areas in China as a symbol of growing rich from a well-off standard. The demand of family cars has increased strongly, but market competition is also aggravated increasingly. As the continuous reduction of the sales prices, the profits of cars' production enterprises were also depressed. As a result, to increase benefits, the key is to reduce cars' cost. Generally, about $60 \%-70 \%$ of production cost is decided implicitly during the design stage ${ }^{l}$. So the cost estimation in the design stage is crucial.

With the crisis of petroleum, customers consider not only the purchase price of the car but also the expense in use. Therefore in this paper, through a

Please use the following format when citing this chapter:

Chen, Xiaochuan, Shao, Jun, Tian, Zhongxu, 2006, in International Federation for Information Processing (IFIP), Volume 207, Knowledge Enterprise: Intelligent Strategies In Product Design, Manufacturing, and Management, eds. K. Wang, Kovacs G., Wozny M., Fang M., (Boston: Springer), pp. 610-618. 
review of the car's design, the artificial neural networks (ANN) method of back-propagation model based on feature is selected to establish a model to estimate life cycle cost (LCC) and some performances of cars at the conceptual design stage from the viewpoint of design for cost (DFC). The estimation results can help designers enhance the accuracy of the LCC estimation.

\section{BRIEF DISCUSSION OF DFC}

Design for Cost (DFC) is a design method which analyzed and evaluated the product's life cycle cost (include manufacturing cost, sale cost, use cost, maintenance cost, recycle cost, etc.), then modified the design to reduce the life cycle $\operatorname{cost}^{2}$. DFC need confirming parameters of manufacturing, usage, maintenance phases, for example, assembly cost percent unit, usage cost percent unit. Designer should balance performance, schedule, reliability, LCC and so on. In DFC, LCC serve as a critical parameter for design and provide support tools for designers to analyze and evaluate cost. For more details about DFC, please refer to Methodology and technology of design for $\operatorname{cost}(\mathrm{DFC})^{3}$.

The cost in DFC refers to LCC, which consists of the total expense of research, design, development, production, usage, maintenance and disuse used in a large range from plan, argumentation, research, design, development, production, usage, maintenance to the final disuse phases ${ }^{4,5}$. The concept of LCC is first presented and then used by DoD (Department of Defense). In a typical weapon system, the cost of usage and maintenance occupy about $75 \%$, so the research for LCC must be conducted then. But the technique developed by DoD aim at purchase instead of design. LCC include plan cost, manufacturing cost, sale cost, maintenance cost, use cost, recycle and disuse cost, while design cost occupies about 10\%-15\%, manufacturing cost $30 \%-35 \%$, use and maintenance cost $50 \%-60 \%$, others less than $5 \%{ }^{5}$.

\section{ANALYSIS OF LCC FEATURES}

\subsection{Selection of LCC Estimation Methods}

In order to reduce the LCC of a product, the key is to adopt a proper method to estimate it. In the conceptual design stage, design information is not integrated and is uncertain highly. For example, material information is 
not decided basically; machining process is considered roughly and is not include detail information. In this case it is difficult for us to translate highly uncertain design feature into detail cost feature. Therefore in this paper the ANN method based on feature is selected according to the character of conceptual design.

1. Identify cost-related features, such as: material, process, product structure, tolerance etc.

2. Classify and quantify the identified features. As the value of feature input into the neural network is usually between $0-1$, a method called quantification must be conducted to deal with the value in practice.

3. Construct and train neural network.

4. Train and adjust the weight of neural network continuously in practice. The advantages of this method are as follows:

1. No need of detailed machining time.

2. No need of cost function in practice, due to the self-study ability to real cost statistics of ANN.

3. The cost estimation among different designs at the conceptual stage can help to improve design.

4. From the viewpoint of DFC, in order to conduct cost estimation in the design stage, the design feature of family cars need to be transformed into cost features, namely, feature mapping ${ }^{6}$. Using neural network method, mapping can be realized automatically and then decrease the work of people consequently.

\subsection{The presentation and application of neural network ensemble}

Hansen and Salamon first presented the trailblazing method of neural network ensemble in 1990. They proved that the generalization ability can be prominently improved simply by training several neural networks and combining their results in some way. Sollich and Krogh defined neural network ensemble as a collection of a (finite) number of neural networks or other type of predictors that are trained for the same task ${ }^{7}$. Now, this definition has been widely acknowledged.

Perrone and Cooper proved in 1993 that, compared with the mean value of each network's generalization error, ensemble generalization error decrease by $\mathrm{N}$ times when merge regression estimation with neural network ensemble, if simply mean is adopted and error of each network is independent random variable and their likelihoods are zero. Here, $\mathrm{N}$ refers to the number of network included ${ }^{8}$.

It's an easy trap for some common-used neural networks to fall into local minimum during its study, which is considered to be one of the biggest 
weaknesses for neural networks. But Perrone and Cooper argue that this characteristic play an important role for neural network in the promotion of its generalization ability. Since these neural networks are uncorrelated to each other, they will easily be trapped by local minimum. Thus the variance of neural network ensemble should be pretty big and then reduce generalization error. In other words, the negative effect of each local minimum counteracts in the end. All the networks included in the neural network ensemble give the same or approximate outputs to the same input. At this moment the diversity factor of the ensemble is close to zero while its generalization error is close to the weighted average of each network's generalization error. On the contrary, if the network included in the ensemble is independent, then the diversity factor of the ensemble will be pretty big, and its generalization error will be far smaller than the weighted average of each network's generalization error. Consequently, to enhance the generalization ability of neural network, the errors in the ensemble should be as uncorrelated to each other as possible.

\subsection{Obtain the design features of family cars}

Vehicle design process included conceptual design, technology design, trial-manufacture and sales stage ${ }^{9}$. In this paper we research the earlier stage of conceptual design. At this stage the following features can be confirmed in a car: general dimension/size, wheelbase, engine and so on. Considering DFC theory and some facts, we pick volume (length, width, and height), engine's parameter, car's weight, feature of electronic equipment and actuating feature as design characters. But in consideration of the difficulty in data-collecting and the characteristics to the conceptual design stage, we select these parameters: length, width, high, wheelbase, maximum power, maximum twisting moment/ torque and exhaust quantity.

Because it is difficult to collect LCC data, we compute use cost by oil/100KM , $100 \mathrm{KM} /$ day and 10 years in this paper. Then we get LCC adding sale price to usage expense. The data of this paper are obtained through Internet, which may not be fully accurate, but that's definitely enough to illustrate the feasibility of our method. 


\section{A CASE ABOUT FAMILY CAR'S LCC ESTIMATION BASED ON NEURAL NETWORK ENSEMBLE}

\subsection{Structure of Back Propagation ANN}

Pilot calculation has been conducted first so as to compare the parameter selected. 3-layer structure is applied as the structure of Back Propagation (BP) ANN. The number of input units is the same with that of input features, and the number of hidden units is 1 more than that of input features while there is only 1 output number: LCC. Namely, input units number are 7, hidden units number are 8 . The training error is 0.001 . To facilitate programming, the neural network tool box of MATLAB 6.5 is chosen to carry out some relevant calculations.

\subsection{Collection and choice of samples}

We collected 19 groups' data of economic family cars on Internet. In this paper we adopt 12 groups of data as train sample of ANN, 7 groups as inspection sample of ANN. The output value of train samples are:

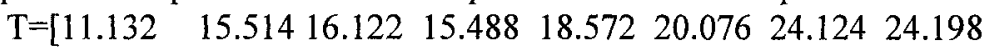

$\begin{array}{llll}37.29 & 35.788 & 21.133 & 40.074]\end{array}$ Unit: 10thou. Yuan

ANN value of inspection samples are :

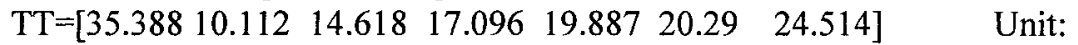
10thou. Yuan

\subsection{The training and LCC estimation of neural network}

The train algorithm of traditional BP ANN adopts Gradient Descent. Its rapidity of convergence is slow and it is easy to fall into local minimum value. We have applied improved train algorithm, namely, LevenbergMarquardt (LM) algorithm and genetic algorithm (GA). The advantage of LM is its swift convergence ability when the quantity of network weights is not too much. It has combined the advantage of Gradient Descent and Newton method. We need point out that there exists local minimum value in this algorithm. Due to the problem of local minimum for all the algorithms applied in this article, repeated train was performed toward the network with different initials. The final calculations were given in Table 1. Through actual application, we discovered that LM and GA methods can get comparatively better results than traditional train algorithm of ANN. 
GA algorithm has a characteristic to convergence at the global optimum, so to optimize the weight of $\mathrm{ANN}$ with it might acquire global optimum result.

Table 1. results on LCC estimation with different train methods

\begin{tabular}{|c|c|c|c|c|c|}
\hline \multirow{3}{*}{ NO. } & \multirow{3}{*}{$\begin{array}{l}\text { LCC } \\
\text { computa } \\
\text { tional } \\
\text { value }\end{array}$} & $\begin{array}{l}\text { Appended } \\
\text { momentum } \\
\text { technique }\end{array}$ & $\begin{array}{l}\text { Momentum } \\
\text { technique } \\
\text { combined with } \\
\text { self-adapting } \\
\text { learning rate }\end{array}$ & LM method & \multirow{2}{*}{$\begin{array}{l}\text { ANN's weight } \\
\text { selection } \\
\text { method based } \\
\text { on GA }\end{array}$} \\
\hline & & $\begin{array}{l}\text { Train } \\
\text { step:21150 } \\
\text { Train error: } \\
1.653\end{array}$ & $\begin{array}{l}\text { Train step } \\
11881 \\
\text { Train error:0.01 }\end{array}$ & $\begin{array}{l}\text { Train step: } 30 \\
\text { Train } \\
\text { error: } 0.001\end{array}$ & \\
\hline & & $\begin{array}{ll}\text { predi } & \text { relativ } \\
\text { ctive } & \text { e } \\
\text { value } & \text { error( } \\
\end{array}$ & $\begin{array}{ll}\text { predic } & \text { relative } \\
\text { tive } & \text { error( } \\
\text { value } & \%)\end{array}$ & $\begin{array}{ll}\text { predic } & \text { relative } \\
\text { tive } & \text { error( } \\
\text { value } & \%)\end{array}$ & $\begin{array}{ll}\text { predic } & \text { relativ } \\
\text { tive } & \mathrm{e} \\
\text { value } & \text { error( } \\
& \% \text { \%) } \\
\end{array}$ \\
\hline 1 & 35.3880 & 39.23610 .8740 & $42.1587 \quad 19.1326$ & $39.3300 \quad 11.1395$ & $27.8739-21.2335$ \\
\hline 2 & 10.1120 & $8.0722-20.1721$ & $11.1669 \quad 10.4321$ & $11.2599 \quad 11.3516$ & $10.8568 \quad 7.3652$ \\
\hline 3 & 14.6180 & 17.95122 .8014 & $15.2406 \quad 4.2590$ & $14.1796-2.9992$ & $16.2908-11.4435$ \\
\hline 4 & 17.0960 & $18.192 \quad 6.4102$ & $15.0595-11.9121$ & $14.5095-15.1295$ & $16.1443 \quad-5.5670$ \\
\hline 5 & 19.8866 & 22.73214 .3060 & $26.9708 \quad 35.6228$ & 25.334927 .3966 & $21.5937 \quad 8.5842$ \\
\hline 6 & 20.2900 & $21.135 \quad 4.1639$ & $24.1018 \quad 18.7867$ & $23.6370 \quad 16.4956$ & $19.8623-2.1079$ \\
\hline 7 & 24.5140 & 36.54149 .0629 & $21.7315-11.3506$ & $24.2586 \quad-1.0417$ & $21.1299-13.8047$ \\
\hline $\begin{array}{l}\text { mean } \\
\text { error }\end{array}$ & $\begin{array}{l}\text { elative } \\
\text { o) }\end{array}$ & 18.256 & 15.928 & 12.222 & 10.0151 \\
\hline
\end{tabular}

We get the LCC estimation result through the application of LM train method and GA train method in Table 1 to apply Neural Network Ensemble. The estimation result is showed in Table 2; we can find mean relative error is obviously smaller than simply use LM method or GA method.

Table 2. Results on LCC estimation of neural network ensemble based on LM train method and $G A$ train method

\begin{tabular}{llll}
\hline \multirow{2}{*}{ NO. } & \multirow{2}{*}{ LCC computational value } & \multicolumn{2}{l}{ Estimation results of neural network ensemble } \\
\cline { 4 - 4 } & & predictive value & relative error $(\%)$ \\
\hline 1 & 35.3880 & 33.60195 & -5.04705 \\
2 & 10.1120 & 11.05835 & 9.358683 \\
3 & 14.6180 & 15.2352 & 4.222192 \\
4 & 17.0960 & 15.3269 & -10.348 \\
5 & 19.8866 & 23.4643 & 17.99051 \\
6 & 20.2900 & 21.74965 & 7.193938 \\
7 & 24.5140 & 22.69425 & -7.42331
\end{tabular}




\begin{tabular}{llll}
\hline NO. LCC computational value & \multicolumn{2}{l}{ Estimation results of neural network ensemble } \\
\cline { 3 - 3 } & predictive value & relative error $(\%)$ \\
\hline mean relative error $(\%)$ & 8.797673 & \\
\hline
\end{tabular}

The content discussed before treat LCC as a whole to estimate, so in the rest part we will estimate usage expense (oil consumption cost) and purchase expense respectively, and then add the latter to the former to obtain the estimation result. Because the effect of LM train method and GA train method is pretty good, the following estimation use them respectively. From the comparison of Table 3, Table 4 and Table 1, we can find some errors of estimation value increase while some others decrease without regularity, but all the overall mean errors decrease. The final calculations are given in Table 5 . It can be observed that its mean relative error is the smallest and actually that's the result of neural network ensemble, namely, estimate LCC by neural network: estimates every part of LCC respectively, and then add all of them to obtain LCC which is feasible. Though this method add to the computation quantity, but the information obtained are more abundant than simply estimate the total quantity of LCC.

Table 3. purchase expense and usage expense obtained through LM train method

\begin{tabular}{|c|c|c|c|c|c|c|c|c|c|}
\hline \multirow[b]{3}{*}{ NO. } & \multirow{3}{*}{$\begin{array}{l}\text { LCC } \\
\text { comput } \\
\text { ational } \\
\text { value }\end{array}$} & \multicolumn{3}{|c|}{ Purchase expense } & \multicolumn{3}{|c|}{ Usage expense } & \multirow{2}{*}{\multicolumn{2}{|c|}{ LCC estimation }} \\
\hline & & \multicolumn{3}{|c|}{$\begin{array}{l}\text { train step: } 40 \\
\text { train error: } 0.001\end{array}$} & \multicolumn{3}{|c|}{$\begin{array}{l}\text { train step: } 24 \\
\text { train error: } \quad 0.001\end{array}$} & & \\
\hline & & $\begin{array}{l}\text { actual } \\
\text { value }\end{array}$ & $\begin{array}{l}\text { predic } \\
\text { tive } \\
\text { value }\end{array}$ & $\begin{array}{l}\text { relative } \\
\text { error( } \\
\%)\end{array}$ & $\begin{array}{l}\text { actual } \\
\text { value }\end{array}$ & $\begin{array}{l}\text { predic } \\
\text { tive } \\
\text { value }\end{array}$ & $\begin{array}{l}\text { relative } \\
\text { error( } \\
\%)\end{array}$ & $\begin{array}{l}\text { predic } \\
\text { tive } \\
\text { value }\end{array}$ & $\begin{array}{l}\text { relativ } \\
\mathrm{e} \\
\text { error( } \\
\%) \\
\end{array}$ \\
\hline 1 & 35.3880 & 24.000 & 31.558 & 31.490 & 11.388 & 12.581 & 10.4775 & 44.138 & 24.727 \\
\hline 2 & 10.1120 & 3.9800 & 5.0449 & 26.756 & 6.1320 & 5.9085 & -3.6446 & 10.953 & 8.3208 \\
\hline 3 & 14.6180 & 6.8800 & 7.1125 & 3.3797 & 7.7380 & 7.0825 & -8.4709 & 14.195 & -2.8937 \\
\hline 4 & 17.0960 & 10.380 & 6.5844 & -36.567 & 6.7160 & 8.8224 & 31.3644 & 15.407 & -9.8806 \\
\hline 5 & 19.8866 & 10.820 & 12.004 & 10.940 & 9.0666 & 8.3671 & -7.7149 & 19.719 & -0.8448 \\
\hline 6 & 20.2900 & 10.800 & 11.977 & 10.898 & 9.4900 & 9.0846 & -4.2721 & 21.062 & 3.8023 \\
\hline 7 & 24.5140 & 12.980 & 11.977 & -7.6677 & 11.534 & 11.566 & 0.2759 & 23.543 & -3.9622 \\
\hline \multicolumn{2}{|c|}{$\begin{array}{l}\text { mean relative } \\
\text { error }(\%)\end{array}$} & \multicolumn{3}{|c|}{18.2426} & \multicolumn{3}{|c|}{9.4601} & \multicolumn{2}{|c|}{7.7758} \\
\hline
\end{tabular}

Table 4. purchase expense and usage expense obtained through GA train method

\begin{tabular}{|c|c|c|c|c|c|c|c|c|c|}
\hline \multirow{3}{*}{ NO. } & \multirow{3}{*}{$\begin{array}{l}\text { LCC } \\
\text { comput } \\
\text { ational } \\
\text { value }\end{array}$} & \multicolumn{3}{|c|}{ Purchase expense } & \multicolumn{3}{|c|}{ Usage expense } & \multirow{2}{*}{\multicolumn{2}{|c|}{ LCC estimation }} \\
\hline & & $\begin{array}{l}\text { Evolut } \\
\text { numbe } \\
\text { train er }\end{array}$ & $\begin{array}{l}\text { on gener } \\
25 \\
\text { or: } 28.7\end{array}$ & & $\begin{array}{l}\text { Evolut } \\
\text { numbe } \\
\text { train er }\end{array}$ & $\begin{array}{l}\text { on genera } \\
25 \\
\text { or: } 14.6\end{array}$ & & & \\
\hline & & $\begin{array}{l}\text { actual } \\
\text { value }\end{array}$ & $\begin{array}{l}\text { predic } \\
\text { tive } \\
\text { value }\end{array}$ & $\begin{array}{l}\text { relative } \\
\text { error( } \\
\% \text { ) }\end{array}$ & $\begin{array}{l}\text { actual } \\
\text { value }\end{array}$ & $\begin{array}{l}\text { predic } \\
\text { tive } \\
\text { value }\end{array}$ & $\begin{array}{l}\text { relative } \\
\text { error( } \\
\%)\end{array}$ & $\begin{array}{l}\text { predic } \\
\text { tive } \\
\text { value }\end{array}$ & $\begin{array}{l}\text { elative } \\
\text { error( } \\
\%)\end{array}$ \\
\hline 1 & 35.3880 & 24.000 & 23.1705 & -3.4561 & 11.3880 & 12.5943 & 10.5931 & 35.7648 & 1.06477 \\
\hline
\end{tabular}




\begin{tabular}{|c|c|c|c|c|c|c|c|c|c|}
\hline \multirow{3}{*}{ NO. } & \multirow{3}{*}{$\begin{array}{l}\text { LCC } \\
\text { comput } \\
\text { ational } \\
\text { value }\end{array}$} & \multicolumn{3}{|c|}{ Purchase expense } & \multicolumn{3}{|c|}{ Usage expense } & \multirow{2}{*}{\multicolumn{2}{|c|}{ LCC estimation }} \\
\hline & & \multicolumn{3}{|c|}{$\begin{array}{l}\text { Evolution generation } \\
\text { number: } 25 \\
\text { train error: } 28.7 \%\end{array}$} & \multicolumn{3}{|c|}{$\begin{array}{l}\text { Evolution generation } \\
\text { number: } 25 \\
\text { train error: } 14.6 \%\end{array}$} & & \\
\hline & & $\begin{array}{l}\text { actual } \\
\text { value }\end{array}$ & $\begin{array}{l}\text { predic } \\
\text { tive } \\
\text { value }\end{array}$ & $\begin{array}{l}\text { relative } \\
\text { error( } \\
\%)\end{array}$ & $\begin{array}{l}\text { actual } \\
\text { value }\end{array}$ & $\begin{array}{l}\text { predic } \\
\text { tive } \\
\text { value }\end{array}$ & $\begin{array}{l}\text { relative } \\
\text { error( } \\
\%)\end{array}$ & $\begin{array}{l}\text { predic } \\
\text { tive } \\
\text { value }\end{array}$ & $\begin{array}{l}\text { elative } \\
\text { error( } \\
\%)\end{array}$ \\
\hline 2 & 10.1120 & 3.9800 & 3.5479 & -10.8571 & 6.1320 & 5.4205 & -11.6034 & 8.9684 & -11.3093 \\
\hline 3 & 14.6180 & 6.8800 & 10.9628 & 59.3432 & 7.7380 & 7.1751 & -7.2747 & 18.1379 & 24.0792 \\
\hline 4 & 17.0960 & 10.380 & 9.5297 & -8.1917 & 6.7160 & 7.7368 & 15.2002 & 17.2665 & 0.99731 \\
\hline 5 & 19.8866 & 10.820 & 13.2279 & 22.2542 & 9.0666 & 0.8987 & 20.2067 & 24.1266 & 21.3209 \\
\hline 6 & 20.2900 & 10.800 & 11.1698 & 3.4244 & 9.4900 & 9.5213 & 0.3302 & 20.6911 & 1.97684 \\
\hline 7 & 24.5140 & 12.980 & 13.0058 & 0.1986 & 11.5340 & 11.1505 & -3.3251 & 24.1563 & -1.45917 \\
\hline \multicolumn{2}{|c|}{$\begin{array}{l}\text { mean relative } \\
\text { error }(\%)\end{array}$} & \multicolumn{3}{|c|}{15.3893} & \multicolumn{3}{|c|}{9.7905} & \multicolumn{2}{|r|}{8.8868} \\
\hline
\end{tabular}

Table 5. Results on LCC estimation of neural network ensemble based on purchase expense and usage expense

\begin{tabular}{|c|c|c|c|c|c|c|c|}
\hline \multirow[t]{2}{*}{ NO. } & \multirow{2}{*}{$\begin{array}{l}\text { LCC } \\
\text { computa } \\
\text { tional } \\
\text { value }\end{array}$} & \multicolumn{2}{|c|}{$\begin{array}{l}\text { LCC value estimated } \\
\text { through LM method }\end{array}$} & \multicolumn{2}{|c|}{$\begin{array}{l}\text { LCC value estimated } \\
\text { through GA method }\end{array}$} & \multicolumn{2}{|c|}{$\begin{array}{l}\text { LCC value estimated } \\
\text { through neural } \\
\text { network ensemble }\end{array}$} \\
\hline & & $\begin{array}{l}\text { Predictive } \\
\text { value }\end{array}$ & $\begin{array}{l}\text { relative } \\
\text { error }(\%)\end{array}$ & $\begin{array}{l}\text { Predictive } \\
\text { value }\end{array}$ & $\begin{array}{l}\text { relative } \\
\text { error(\%) }\end{array}$ & $\begin{array}{l}\text { Predictive } \\
\text { value }\end{array}$ & $\begin{array}{l}\text { relative } \\
\text { error(\%) }\end{array}$ \\
\hline 1 & 35.3880 & 44.1382 & 24.7265 & 35.7648 & 1.06477 & 39.9515 & 12.89561 \\
\hline 2 & 10.1120 & 10.9534 & 8.3208 & 8.9684 & -11.30934 & 9.9609 & -1.49426 \\
\hline 3 & 14.6180 & 14.1950 & -2.8937 & 18.1379 & 24.0792 & 16.16645 & 10.59276 \\
\hline 4 & 17.0960 & 15.4068 & -9.8806 & 17.2665 & 0.99731 & 16.33665 & -4.44168 \\
\hline 5 & 19.8866 & 19.7186 & -0.8448 & 24.1266 & 21.3209 & 21.9226 & 10.23805 \\
\hline 6 & 20.2900 & 21.0615 & 3.8023 & 20.6911 & 1.97684 & 20.8763 & 2.889601 \\
\hline 7 & 24.5140 & 23.5427 & -3.9622 & 24.1563 & -1.459166 & 23.8495 & -2.7107 \\
\hline \multicolumn{2}{|c|}{$\begin{array}{l}\text { mean relative } \\
\text { error }(\%)\end{array}$} & \multicolumn{2}{|c|}{7.7758} & \multicolumn{2}{|c|}{8.8868} & \multicolumn{2}{|c|}{6.466096} \\
\hline
\end{tabular}

Reference 10 hold the view that in the data acquisition process, requirement change in the various phases and product information keep enriched. Because information are unavailable and incomplete during conceptual design stage, the accuracy of cost estimation range from $-30 \%$ to $+50 \%$; When design information are further enriched, and the historical data resembling to current design are available, the accuracy of estimation can achieve $-15 \% \sim+30 \%$; According to the results of LCC estimation in this paper, error is well controlled between $-5 \%$ to $+13 \%$. 


\section{CONCLUSIONS}

This paper adopt self-adapting learning rate, LM algorithm and genetic algorithm respectively to train Back Propagation neural networks, LCC estimation was made for economically family cars through the application of neural network ensemble method. The results obtained through the adoptions of neural network ensemble is better than simply use genetic algorithm or LM algorithm, and we can easily find that its computational results are pretty stable, with mean error between $7 \%$ to $9 \%$ while other methods such as LM is not quite stable.

In order to better estimation LCC and function index to conformed them to the real practice, Something more can be research in the fields of enterprise size, repair and maintenance etc. We are fully convinced that the application of these methods must lead to the reduction of family car's LCC and actively enhance the level of design.

\section{REFERENCES}

1. S. Dowlatshahi, "Product design in a concurrent engineering environments an optimisation approach", Journal of Production Research, 30(8), 1803-1818(1992).

2. Xiao-chuan Chen, ZhangBao-bao,Feng Xin-an, Key technology and conceptual model about design for cost(DFC), Journal of Dalian University of Technology,39(6),775780(1999). ( in Chinese)

3. Chen Xiaochuan, Yang Jianguo, Li Beizhi, Feng Xin-an. Methodology and technology of design for cost (DFC), The 5th World Congress on Intelligent Control and Automation, (WCICA'04) Hangzhou, China, June 14-18, (2004) pp. 3129-3134.

4. Benjamin S. Blanchard. Life cycle costing-A review, Terotechnica, 1,9-15(1979).

5. Chen Xiao-chaun, "Research on theories and methods of Design For Cost(DFC) in concurrent engineering", Dalian University of Technology, Ph. D. Dissertation. (2000). (in Chinese)

6. Chen Xiaochuan, Fang Minglun, Feng Xinan. Application of multiple domain feature mapping in Design For Cost(DFC), CE2002, Cranfield University, U.K. July, 27-31, (2002).

7. P. Sollich, A. Krogh. Learning with ensembles: How over fitting can be useful. In: Advances in Neural Information Processing Systems, edited by D Touretzky, M Mozer, M Hasselmo. (Cambridge, MA: MIT Press, 1996), pp.190- 196.

8. M. P. Perrone, L. N. Cooper. When networks disagree: Ensemble method for neural networks. In: Artificial Neural Networks for Speech and Vision, edited by Mammone R J (New York: Chapman \& Hall, 1993), pp. 126- 142.

9. Wangyu Wang, Automobile design (fourth edition), (Beijing: China Machine Press.2004).

10. R. C. Creese, L. T. Moore, Cost modeling for concurrent engineering, Cost Engineering ,32(6),23-27(1990). 